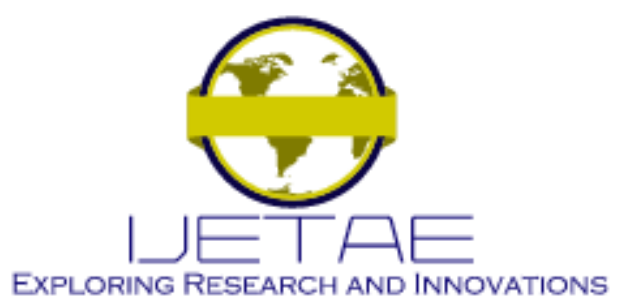

International Journal of Emerging Technology and Advanced Engineering

Website: www.ijetae.com (E-ISSN 2250-2459, Scopus Indexed, ISO 9001:2008 Certified Journal, Volume 11, Issue 12, December 2021)

Manuscript Received: 08 November 2021, Received in Revised form: 07 December 2021, Accepted: 12 December 2021 DOI: 10.46338/ijetae1221_20

\title{
Analysis and Reporting System Point of Sales for Food and Beverage $(\mathrm{F} \& \mathrm{~B})$
}

\author{
Cavell Angga Widjaja ${ }^{1}$, Christian Timotius Wahyudi ${ }^{2}$, Violitta Yesmaya ${ }^{3}$, Dennise Adrianto ${ }^{4}$ \\ Computer Science Department, School of Computer Science, Bina Nusantara University, Jakarta Indonesia 11480
}

\begin{abstract}
A point of sale (POS) is a cashier system that is used to record every sale that happens in a process where goods and services are traded. POS application is focused on the F\&B (Food and Beverages) market. The POS application itself is a mobile-based application that runs on the iOS platform developed using the Extreme Programming method. Aside from the application has a back-end web system that contains the sales reports and the statistics of the restaurant. The main goal of this system is to help restaurant owners recap their sales, evaluate their menu, and increase restaurant security by reducing the numbers of errors, negligence, and fraud that can and may occur. This study explains the details of the design and implementation of the POS application and provides a review of the system by the restaurants that have used this system. Overall, the results achieved according to the users includes an increase in terms of energy and time efficiency from a restaurant operations standpoint as well as increased safety and accuracy.
\end{abstract}

Keywords - POS, Food and Beverages, iOS, Extreme Programming.

\section{INTRODUCTION}

Information technology is one of the rapidly growing fields today. The most felt technological development today is communication; to communicate everyone can easily use smartphones. With the smartphone makes it easier to communicate and can solve problems by using the existing application on the smartphone.

Smartphone has its own system that makes it run as you wish or what is commonly referred to as an operating system. Like computers with well-known operating systems such as Windows and Linux, one of the smartphone operating systems that is currently developing a trend is iOS, which was designed by the Apple company for iPhone smartphones or iPad tablets. The iOS operating system is known as UI / UX (User Interface / User Experience) which is simple and easy to understand. Apart from that, iOS seems to understand very well about usability which is not excessive graphics and animation but more in terms of functionality and simple thinking [1].
In developing the current smartphone application system, one of the impacts is the food industry. The food industry or what is commonly known as Food and Beverage $(\mathrm{F} \& \mathrm{~B})$ is one of the most rapidly developed industries. With the economic crisis in the world, the F\&B industry is arguably one of the fastest growing industries; so many young entrepreneurs have started trying to invest in this industry.

To run a business in the restaurant industry, restaurant owners have an obligation to organize their restaurant so that it can run smoothly and stably. These obligations will be carried out more easily if they have a system and neatness that they build. The following systems include monthly sales reports, cashier management, employee management, and stock management.

Many restaurant support innovations have been developed to make the restaurant operational system easier. This restaurant operational system is a Point of Sales or commonly called POS. POS itself means a point of sale where the transaction is completed with the customer making payments in exchange for goods or services. POS is better known as a cashier system. Most of the sales places ranging from minimarkets, supermarkets, clothing stores to restaurants usually implement POS into their sales to facilitate transactions, from cash registers to special machines such as computers that have software to run POS functions [2].

The POS system itself is still developing until now there are POS innovations in the form of mobile applications [3]. Mobile POS is currently on the rise in the information technology industry and one of the advantages that makes mobile POS can beat POS in computer form is flexibility and cost. POS mobile can use a tablet or smartphone, can be carried anywhere, and does not require a lot of space. In terms of price, mobile POS costs much less than computers because of the high cost of computer hardware compared to a smartphone or tablet.

The majority of restaurants and cafes now have switched from POS system that uses a computer into a mobile POS system. 


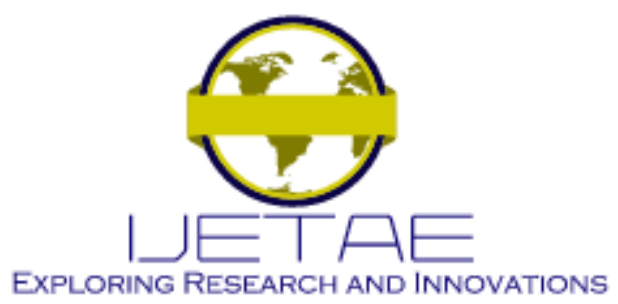

International Journal of Emerging Technology and Advanced Engineering

Website: www.ijetae.com (E-ISSN 2250-2459, Scopus Indexed, ISO 9001:2008 Certified Journal, Volume 11, Issue 12, December 2021)

With the complete features provided by mobile POS, a restaurant should be able to run with an integrated and more structured system. However, the reality is the opposite, most of the restaurants that have been visited still do a lot of manual calculations such as the calculation of the stock, capital, and net profit.

For cafes and restaurants, usually the owner still manages the restaurant in the field, starting from being a waiter, cashier, brewer or just supervising their restaurant. Generally, at the end of the month, restaurant owners conduct an evaluation of their restaurant, from service performance, sales, menu variations, and inventory taking.

Stock taking is one of the evaluations conducted by restaurant owners based on each specified period, generally at the end of each month. Restaurant owners to know the ingredients needed to maintain the availability of the ingredients used. Even the restaurant sometimes purchases excess goods so that many ingredients are actually rarely used but are always purchased every month, causing certain ingredients to be excessive. And errors often occur in recording customer orders by restaurant waiters, which can cause losses for the restaurant.

By utilizing technology to create a POS application that has a function to support the sustainability of the restaurant's operational system, it is hoped that it will make it easier for restaurant owners to manage a restaurant.

\section{RESEARCH METHOD}

\section{A. Point of sale}

The term Point of Sale is a system of places of sale designed to read information from consumer bills or transactions made by consumers [4].

\section{B. Agile Extreme Programming}

Agile method is a method that can respond to changes quickly. Agile methods can quickly adapt new requirements if there is a change in requirements in the program it is working on. Extreme Programming is one of the methods included in agile methods. In Extreme Programming (XP), there are four phases of activity that is planning, design, coding and testing [5].

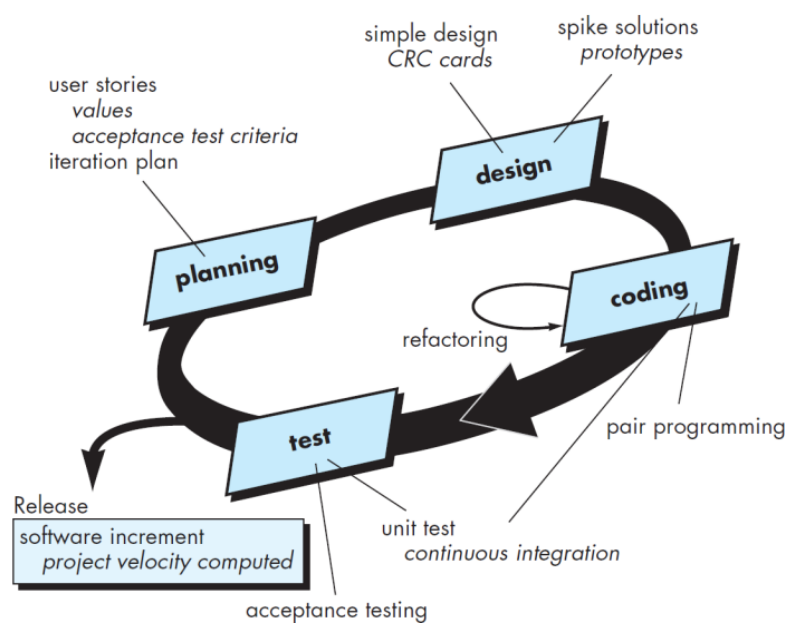

Figure 1. Extreme Programming

Extreme programming can be divided into stages as follows:

\section{Planning}

The planning stage is carried out by creating a user story that describes the output, features and functionality of the software being made.

\section{Design}

Design on XP is done by following the principle of Keep It Simple (KIS). Simpler designs are always preferred over complex designs. For difficult designs, XP will use the Spike Solution where the design is made straight to the point. XP also supports refactoring where the system software is changed in such a way as to change the code structure and simplify the code.

\section{Coding}

This XP stage begins with building a series of unit tests, after which the developer must focus on the implementation to pass the test. In XP the term Pair Programming is also introduced where the process of writing programs is carried out in pairs. Two programmers work together on one computer to write programs. By doing this you will get real-time problem solving and realtime quality assurance. 


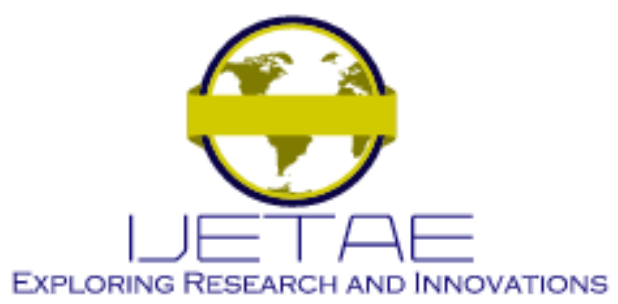

International Journal of Emerging Technology and Advanced Engineering

Website: www.ijetae.com (E-ISSN 2250-2459, Scopus Indexed, ISO 9001:2008 Certified Journal, Volume 11, Issue 12, December 2021)

\section{Testing}

Testing is done by testing the code on unit testing.

\section{Swift 4}

Swift is a programming language introduced by Apple at the World Wide Developers Conference (WWDC) in 2014. At WWDC 2015, Apple announced Swift 2, a major improvement over Swift 1. Swift 3 was released in 2016, which is a further development of Swift 2 and not compatible with the previous version output. The main goal of Swift 3 is for Swift to be source-compatible with all platforms, so that code written on one platform can run on another. This means that code written in macOS can also run on Linux [6].

When Apple first introduced Swift, Apple said Swift was Objective-C without C. Objective-C is a superset of $\mathrm{C}$ and provides object-oriented and dynamic runtime capabilities to the $\mathrm{C}$ language. This means that with Objective-C, Apple must maintain compatibility with the $\mathrm{C}$ language, which hinders development of what can be made to the Objective-C language. Since Swift doesn't need to maintain the same compatibility to $\mathrm{C}$ languages as Objective-C, Apple is free to add features / development to the Swift language.

The table below shows the features that Swift provides compared by Objective-C:

TABLE 1.

SWIFT FeATURES

\begin{tabular}{|l|l|}
\hline Swift Feature & Description \\
\hline Type Interface & $\begin{array}{l}\text { Swift can automatically deduce the type } \\
\text { of a variable or constant, based on the } \\
\text { initial value. }\end{array}$ \\
\hline Generics & $\begin{array}{l}\text { Generics allow us to write code only } \\
\text { once to perform identical tasks for } \\
\text { different types of object. }\end{array}$ \\
\hline $\begin{array}{l}\text { Collection } \\
\text { mutability }\end{array}$ & $\begin{array}{l}\text { Swift does not have separate objects for } \\
\text { mutable or nonmutable containers. } \\
\text { Instead, you define mutability by } \\
\text { defining the container as a constant or } \\
\text { variable. }\end{array}$ \\
\hline Closure syntax & $\begin{array}{l}\text { Closures are self-contained blocks of } \\
\text { functionality that can be passed around } \\
\text { and used in our code. }\end{array}$ \\
\hline Swift Feature & Description \\
\hline Optionals & $\begin{array}{l}\text { Optionals define a variable that might not } \\
\text { have a value }\end{array}$ \\
\hline Switch statement & $\begin{array}{l}\text { The Switch statement has been } \\
\text { drastically improved }\end{array}$ \\
\hline
\end{tabular}

\begin{tabular}{|l|l|}
\hline Swift Feature & Description \\
\hline Tuples & $\begin{array}{l}\text { Functions can have multiple return types } \\
\text { using tuples. }\end{array}$ \\
\hline $\begin{array}{l}\text { Operator } \\
\text { overloading }\end{array}$ & $\begin{array}{l}\text { Classes can provide their own } \\
\text { implementation of existing operators. }\end{array}$ \\
\hline $\begin{array}{l}\text { Enumerations } \\
\text { with associated } \\
\text { values }\end{array}$ & $\begin{array}{l}\text { In Swift, we can do a lot more than just } \\
\text { define a group of related values with } \\
\text { enumerations }\end{array}$ \\
\hline $\begin{array}{l}\text { Protocols and } \\
\begin{array}{l}\text { Protocol- } \\
\text { oriented Design }\end{array}\end{array}$ & $\begin{array}{l}\text { Apple introduced the Protocol-oriented } \\
\text { Programming paradigm with Swift } \\
\text { vriting applications but also changes } \\
\text { how we think about programming }\end{array}$ \\
\hline
\end{tabular}

Swift 4 is used to develop a POS system that will be implemented on the iOS platform. Swift 4 is only for system development for the front end display that users use on iOS mobile devices

\section{D. $P H P$}

PHP: Hypertext Preprocessor (PHP) is a programming language used to allow servers to generate dynamic output, which is potentially different output every time a browser requests a page [7]. In this study, PHP was developed which is useful for building analysis and report results in the form of statistics which are calculated automatically by the system. The use of PHP is only for the back end of the system that will display a summary of each ingredient used in selling menus at restaurants. Displays the results of the analysis of the menus that are often sold at the restaurant. Which can be used for the analysis needs of the restaurant

\section{E. Laravel}

Laravel is a robust and flexible PHP framework. The framework has a growing community and broad ecosystem of tools, and as a result Laravel is growing in both appeal and reach [8]. Laravel is the framework used in the development of the back end of this POS system.

\section{F. $M y S Q L$}

MySQL is a SQL client/server relational database management system originating from Scandinavia. MySQL includes an SQL server, client programs for accessing the server, administrative tools, and a programming interface for writing your own programs [9]. MySQL is a database storage that is used to store the results of sales transactions, which exist in this POS system. So that all sales transactions can be analysed and generate reports to the restaurant. 


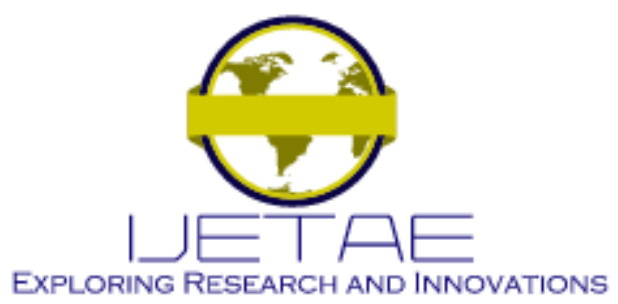

International Journal of Emerging Technology and Advanced Engineering

Website: www.ijetae.com (E-ISSN 2250-2459, Scopus Indexed, ISO 9001:2008 Certified Journal, Volume 11, Issue 12, December 2021)

\section{RESUlTS AND Discussion}

The following are the development stages of Extreme programming $(\mathrm{XP})$ in this study:

\section{a. Planning}

At this planning stage, a process of analysing problems and needs is carried out and what is needed by the restaurant to manage the restaurant from a management, operational and integrated perspective.

\section{b. Design}

After analysing the problems and needs required by the restaurant, then the system is designed using the data that has been obtained. At this design stage, the design stage is carried out to design the User Interface

\section{c. Coding}

At this coding stage, the design that has been designed will be implemented, or it can be called the application development process. The development process uses the XCode platform and the Swift 4 language for mobile applications and Laravel for the web.

\section{d. Test}

At the testing stage, mobile and web application trials will be carried out. Testing is done to find out whether the application and the web are running smoothly as expected and without errors so as not to hinder them during the implementation stage. If it is as expected, then the application can be optimally used by users according to functionality.

The results of this study are an iOS-based mobile application and a back-end website. This system was developed with several system specifications where there are hardware and software system specifications, with the following description:

TABEL 1.

IOS APP HARDWARE SPECIFICATIONS

\begin{tabular}{|l|l|}
\hline \multicolumn{1}{|c|}{ Category } & \multicolumn{1}{c|}{ Requirements } \\
\hline Device & iPad 9.7-inch \\
\hline Connectivity & Internet Network \\
\hline Memory & $128 \mathrm{MB}$ \\
\hline Storage & $100 \mathrm{MB}$ \\
\hline
\end{tabular}

TABEL 2.

PoS APPLICATION SOFTWARE SPECIFICATIONS

\begin{tabular}{|l|l|}
\hline \multicolumn{1}{|c|}{ Category } & \multicolumn{1}{c|}{ Requirements } \\
\hline Sistem Operasi & iOS \\
\hline Versi Sistem Operasi & iOS 12.0 and above \\
\hline Versi Swift & 3.0 and above \\
\hline
\end{tabular}

Here are some of the display screens of the mobile application and website which displays the features available on this POS application. There are 6 features that can be selected by the user (figure 2).

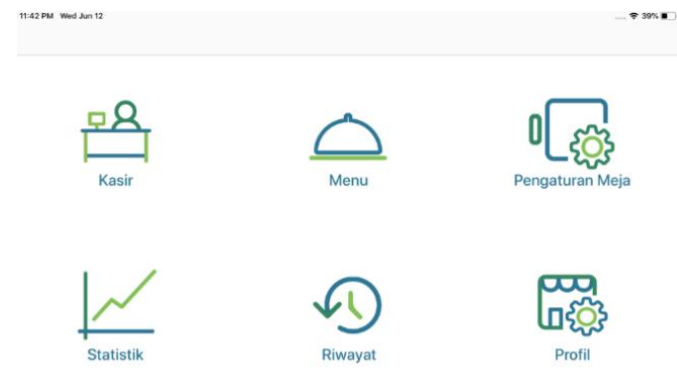

Figure 2. APPLication Main PAge

a. Cashier

The cashier page is used so that users can make new transactions or continue old transactions (figure 3 ).

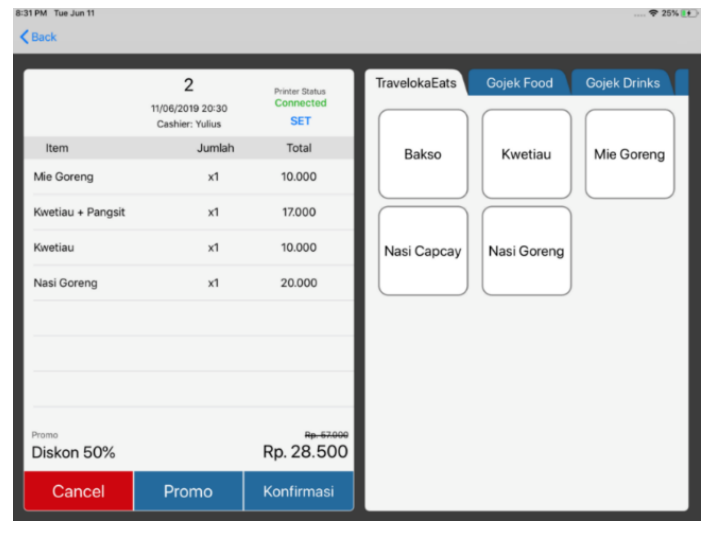

Figure 3. Cashier Page

\section{b. Menu}

Menu page where users can view, add, modify, and delete existing menus and categories (figure 4). 


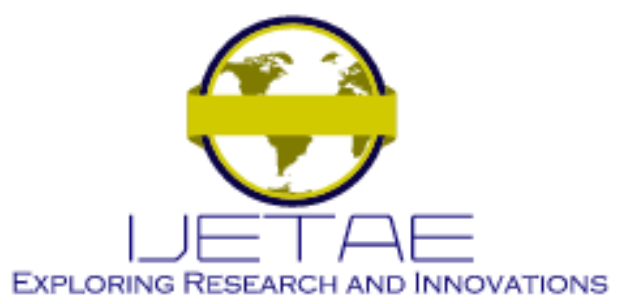

International Journal of Emerging Technology and Advanced Engineering

Website: www.ijetae.com (E-ISSN 2250-2459, Scopus Indexed, ISO 9001:2008 Certified Journal, Volume 11, Issue 12, December 2021)

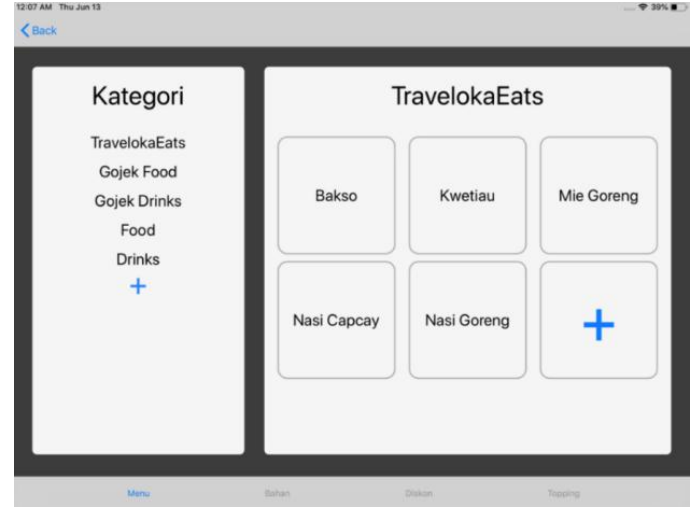

Figure 4. Menu Page

\section{c. Table setting}

Table settings page where users can add, change names, change locations, and delete table layouts from the restaurant layout (figure 5).

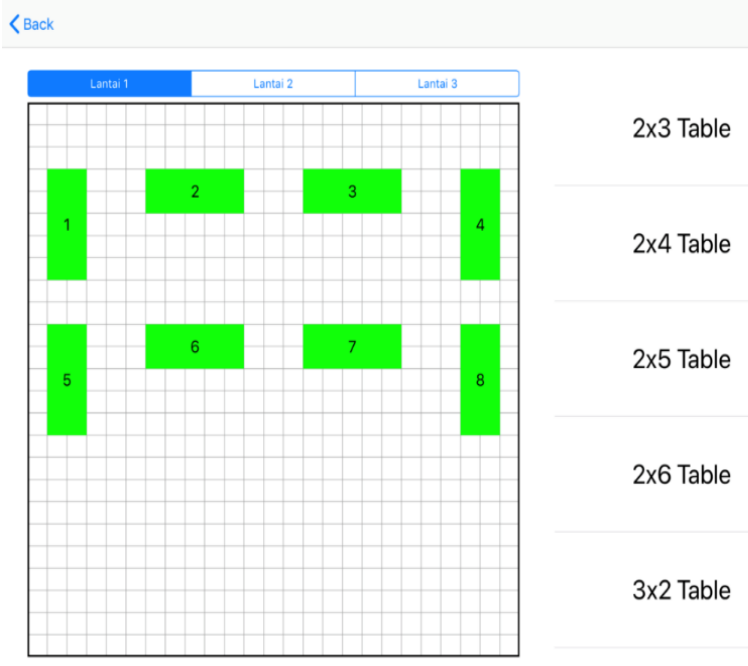

Figure 5. Menu for Table Setting Page

\section{d. Statistics}

The statistics page is used to show the transaction statistics for a certain period that you want to analyse.

\section{e. History}

The history page is a page that shows the transaction history from the period that has been selected, this page is useful to know what the menu is most in demand by consumers (figure 6).

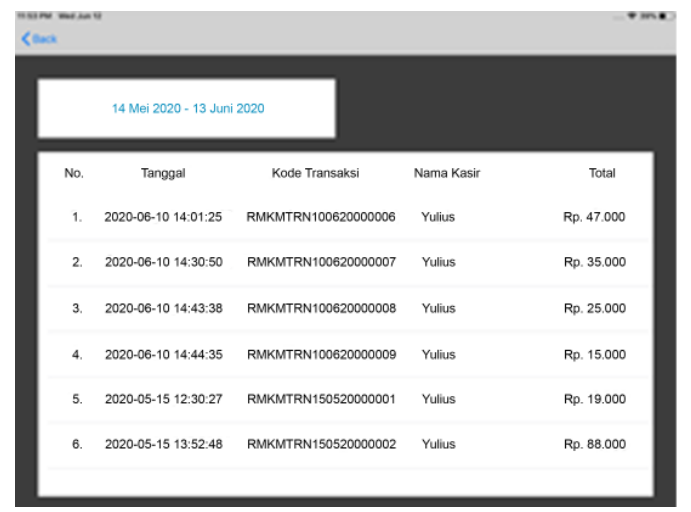

Figure 6. History Page

\section{f. Profile}

The profile page is a page where users can change restaurant profiles, add and update employee data.

The back-end display of the website that is available to users can display complete statistics on the results of restaurant transactions made at a certain time. The results of the analysis and reports of sales transactions can also be seen on the back-end display, along with the ingredients are used on the menu at the restaurant. These statistics will be calculated automatically based on the input period (figure 7).

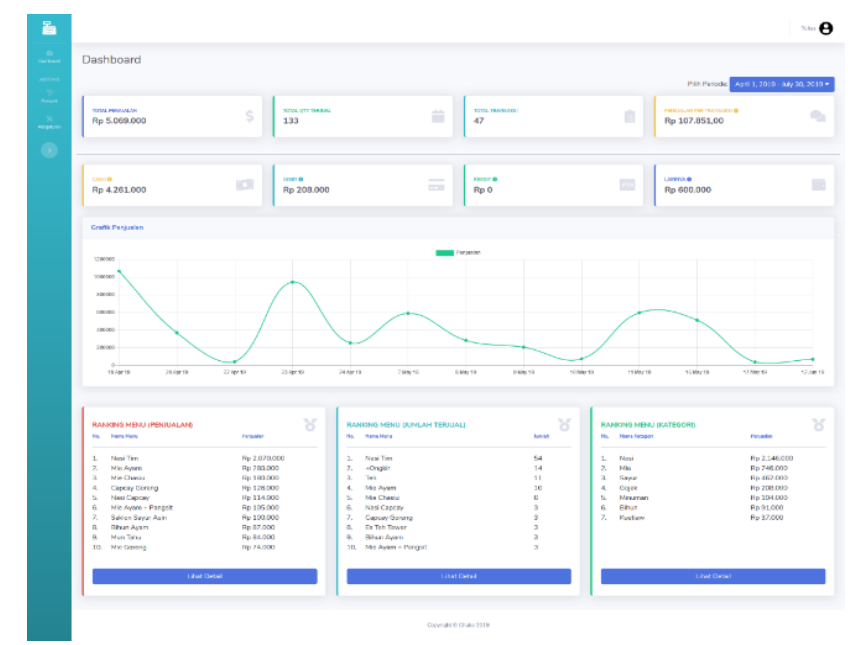

Figure 7. Website Statistics Page

This POS application has been implemented in several restaurants located in Banten, West Java. The author gets positive feedback about the application and also gets suggestions and recommendations for further development. 


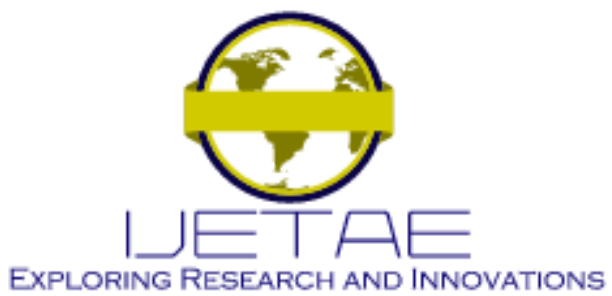

International Journal of Emerging Technology and Advanced Engineering

Website: www.ijetae.com (E-ISSN 2250-2459, Scopus Indexed, ISO 9001:2008 Certified Journal, Volume 11, Issue 12, December 2021)

Overall, this POS application can help the operational systems of restaurant owners.

\section{CONCLUSION}

In this study, the POS application was created on the iOS platform. After analysing, developing, testing, and evaluating, the authors conclude that:

1. The POS application helps restaurant owners or managers evaluate restaurants in terms of ingredients used as well as sales

2. The POS application maintains the security of the business process by monitoring employee performance and avoiding fraud

3. POS application provides essential features in using PoS with table management system and separation between dine-in and dine-out

4. POS applications facilitate and summarize the flow of transactions.

\section{REFERENCES}

[1] Sandström, K. (2011). A study of the iOS. Methods.

[2] Kashima, T., Matsumoto, S., \& Ishii, H. (2010). Recommendation method with rough sets in restaurant point of sales system. Proceedings of the International MultiConference of Engineers and Computer Scientists 2010, IMECS 2010, III, 2018-2023.

[3] Handling, M. F. O. R. (2015). ( 12 ) United States Patent, 2(12).

[4] Edwin Rodriguez. (2012). IIII United States Patent ( 19 ), 85(19), 17.

[5] Pressman, R. s; M. B. (2014). Software Engineering: A Practitioner's Approach 8th Edition. McGraw-Hill Education; 8th Edition.

[6] Hoffman, J. (2017). Mastering Swift 4 - Fourth Edition: An in-depth and comprehensive guide to modern programming techniques with Swift. Packt Publishing; 4th Revised edition.

[7] Nixon, R. (2014). Learning PHP, MySQL \& JavaScript: With jQuery, CSS \& HTML5 (Learning Php, Mysql, Javascript, Css \& Html5). O'Reilly Media; 4th Edition.

[8] Enterprise, J. (2015). Mengenal PHP Menggunakan Framework Laravel. Jakarta: PT Elex Media Komputindo.

[9] DuBois, P. (2013). MySQL. Pearson; 5th Edition. 